\title{
O rap radical e a "nova classe média"
}

\author{
Ricardo Indig Teperman* \\ Universidade de São Paulo, Faculdade de Filosofia, Letras e Ciências Humanas, \\ Departamento de Antropologia Social. São Paulo, SP, Brasil
}

Resumo: Este artigo discute a recente alteração na posição relativa do rap e dos rappers no campo da produção cultural no Brasil. O grupo Racionais MCs, tão central no campo do rap nacional que acaba por determinar a tendência hegemônica do gênero, vem se afastando do posicionamento revolucionário que marcou seus primeiros anos. Proponho que o aumento do poder de consumo e a democratização do acesso à tecnologia e à educação são aspectos que marcam a experiência da nova geração do rap (a chamada "nova escola"), personificada em Emicida, e que provocaram o reposicionamento do Racionais. Recupero uma formulação de Antonio Candido para propor que essa nova posição pode ser considerada "radical".

Palavras-chave: Nova classe média, Sociedade brasileira contemporânea. Racionais MCs, Rap brasileiro, Música Popular Brasileira.

Função fática da linguagem é aquela que tem por objetivo o estabelecimento da comunicação entre emitente e receptor. Numa ligação telefônica, dizemos "oi" ou "alô", então dizemos nosso nome ou perguntamos "quem é" e, no mais das vezes, fazemos perguntas como "tudo bem?". Espera-se uma resposta positiva: "sim, tudo bem", e a partir daí a conversa de fato pode começar.

Na abertura de "Pânico na Zona Sul", primeira faixa do primeiro disco do Racionais MCs, Holocausto Urbano (1990), Edi Rock apresenta os integrantes do grupo: "Ice Blue, Mano Brown, KL Jay e eu". Ele então pergunta: "E aí Mano Brown, certo?". A resposta que ouve não é trivial: "Certo não está, né mano? E os inocentes? Quem os trará de volta?".

Criado em 1988, o Racionais rapidamente se firmou como o principal grupo de rap no Brasil. Se Mano Brown e Edi Rock dividem de maneira equilibrada a autoria das letras, foi o primeiro quem acabou por tomar o lugar de liderança no que diz respeito à imagem externa do grupo. Mais que isso, Brown ocupa uma centralidade no rap que dificilmente se encontra nos outros gêneros de música da mesma forma. Sua declaração de princípios na abertura do primeiro disco - "não está tudo bem" -, dizia muito sobre o posicionamento do grupo e, por extensão, do chamado "rap nacional" diante da indústria cultural. ${ }^{1}$

Os três primeiros discos do grupo ${ }^{2}$ foram produzidos, lançados e distribuídos pelo selo Zimbabwe, de

1 O conceito adorniano é aqui usado de maneira "larga". Penso em grandes gravadoras, grande mídia, etc.

2 Depois de ter duas músicas incluídas na coletânea Hip Hop Cultura de Rua, de 1988, o Racionais lançou os seguintes discos de estúdio: Holocausto Urbano (1990), Escolha seu caminho (1992), Raio-X Brasil (1993), Sobrevivendo no Inferno (1997) e Nada como um dia após um outro dia (2002).

* Autor correspondente: ricardoteperman@yahoo.com.br
William Santiago, fundador da equipe de baile de mesmo nome, que desde os anos 1970 promovia bailes black na cidade de São Paulo (ver Felix, 2005; Macedo, 2007). Por meio de intensa divulgação nas dezenas de rádios comunitárias da periferia, e de centenas de apresentações em clubes, casas de show e vários tipos de palcos improvisados nas "quebradas", o Racionais causou um impacto difícil de dimensionar na juventude das favelas e periferias de São Paulo.

Em 1997, o grupo criou sua própria gravadora, Cosa Nostra, e lançou o CD Sobrevivendo no Inferno, que vendeu mais de 1,5 milhão de cópias. O Racionais construiu sua trajetória sem depender dos mecanismos "centrais" de produção. No mesmo processo, o Capão Redondo, bairro de periferia de São Paulo, tornou-se o centro do rap nacional. $^{2}$

3 De olho em manifestações musicais "excluídas" dos grandes circuitos oficiais, Hermano Vianna $(1988,2006)$ flagra um vício que costuma perturbar os discursos sobre cultura: a suposição de que o centro tem aquilo que falta à periferia. Que existe uma produção cultural elevada no centro e que esta tende a se diluir quanto mais se afasta desse centro.

Trata-se de um sentimento bastante disseminado entre antropólogos, e que podemos chamar de "antipatia pela ideia de centro". Em artigo de 1997, Marshall Sahlins criticou o que chamou de "pessimismo sentimental": a ideia de que a vida dos outros povos do planeta estava desmoronando, sucumbindo à hegemonia ocidental". Ao contrário, Sahlins sugere que estejamos atentos às apropriações locais e ao que ele chama de "indigenização do mundo".

Ainda que as noções de centro e periferia venham sendo repensadas no debate acadêmico contemporâneo, são categorias que continuam operantes. Em texto de apresentação do número dedicado ao tema da "periferia", os editores da revista "Sexta Feira" propõem "não a simples recusa ou aceitação da periferia versus o centro, ou tampouco a impossibilidade de reverter posições que podem se nos revelar de maneira endurecida. Mas sim, reconhecer, no centro, seu devir-periferia, como na periferia, simetricamente, seu devir-centro" (Ferrari, Macedo, \& Hikiji, 2006, p. 5). A revista traz diversos artigos sobre o tema. Ver também Frúgoli Jr., 2000. 
Nos últimos anos, proliferaram os estudos sobre rap, tanto na academia quanto por autores da chamada literatura marginal ${ }^{3}$; o Racionais também ocupa um papel de enorme destaque nessa produção escrita. Há um razoável consenso na bibliografia que buscou dar conta do fenômeno de que a façanha do Racionais e, por extensão, do rap nacional, ${ }^{4}$ foi converter "humilhação em orgulho" (Garcia, 2011). Ao descrever a periferia "de forma positiva, como o espaço da igualdade e da solidariedade, firmadas na miséria e apesar da violência" (Guasco, 2001, p. 90), puderam "simbolizar a experiência de desamparo destes milhões de periféricos urbanos [e] forçar a barra para que a cara deles [dos jovens da periferia] seja definitivamente incluída no retrato atual do país (um retrato que ainda se pretende doce, gentil, miscigenado)" (Kehl, 1999, p. 97). O rap promoveu "o estabelecimento de novas formas de representação social que lhes permite [aos jovens de periferia] expressar seu descontentamento, opor-se à tese da não violência, isto é, de que o Brasil seria uma 'nação diversa, mas não violenta”" (Herschmann, 2005, p. 40).

A novidade do rap foi criar um processo identitário poderoso fora da chave "nacional-patriótica", que havia marcado, por exemplo, a experiência do samba. A favela cantada nos sambas cariocas facilmente se convertia em símbolo da alegria brasileira, em registro ufanista ${ }^{5}$. A periferia cantada pelo Racionais pode, e de fato veio, ganhar dimensão nacional (para além das fronteiras da cidade de São Paulo). Mas o discurso não abandona sua posição de classe, entendida como "grupo social definido, de um lado, pela quantidade de riqueza apropriada e, de outro, por três dimensões de identidade: temporal, cultural e coletiva" (Singer, 2012, p. 27). ${ }^{6}$ As letras do grupo atacam a perpetuação da desigualdade, o racismo ${ }^{7}$, a violência policial e outras mazelas da sociedade brasileira. Mais que isso, assumem um posicionamento forte na luta de classes,

3 Ver Alves, 2004, Buzo, 2010 e Leal, 2007. Para um balanço sobre a produção da literatura periférica, ver Nascimento, 2007.

4 Sugiro que a centralidade do Racionais naqueles anos é tal que formulações mais gerais sobre rap podem servir para se pensar a atuação específica do grupo.

5 A bibliografia sobre samba - e seu desempenho na constituição de uma identidade nacional - é vasta. Ver Vianna (1995), Sandroni (2001) e Wisnik (2004), entre outros. A vertente ufanista a que me refiro está ligada a tradições intelectuais associadas a Gilberto Freyre e às muitas versões da ideia de democracia racial. Ver também Wisnik (2008).

6 Há um enorme debate sobre a pertinência da categoria classe social. Baseio-me aqui no breve balanço sobre o tema realizado por André Singer, que cita a definição proposta aqui e originalmente formulada pelo sociólogo Louis Chauvel, e que constitui um esforço para aproveitar contribuições tanto da tradição marxista quanto da tradição weberiana. Ver Singer 2012.

7 O Racionais assume também uma posição antirracismo, que mereceria ser tratada em um estudo a parte. Entretanto, entendo que a raça é uma categoria que aparece subornidada à categoria "classe", como pode se depreender do refrão do rap "Racistas Otários", lançado no primeiro disco do Racionais: "racistas otários nos deixem em paz; pois as famílias pobres não aguentam mais". em oposição ao que eles próprios entendem como classe dominante.

Rompendo com a versão conciliatória do pacto social brasileiro, o Racionais assumiu uma posição que sugiro considerar revolucionária. Nada mais eloquente do que a legenda foto no encarte do CD Sobrevivendo no Inferno, de 1997, em que os integrantes do grupo são retratados na favela, acompanhados de uma multidão de homens: "apoiados por mais de cinquenta mil manos".

Não se trata apenas de um discurso presente na produção artística do grupo, aspecto tratado por Garcia (2011), mas também de um modo de ação ou inserção social - recusa renitente aos convites da grande mídia e aos contratos publicitários, adesão aos meios de produção (gravadoras, mídia, espaços de apresentação) de sua própria classe. $\mathrm{O}$ grupo atravessou os últimos 25 anos lidando com as contradições intrínsecas a esse conjunto complexo de escolhas e recusas.

O terceiro disco do Racionais, Raio $X$ do Brasil, lançado em 1993, e que contou, pela primeira vez, com uma produção musical que "não era da favela" (os irmãos Newton e Wander Carneiro, do estúdio Atelier), vendeu mais de 80 mil cópias. $O$ grupo ganhou ouvintes nas classes médias, passando a chamar a atenção da grande mídia. Note-se como o posicionamento revolucionário desde cedo encontrava contradições na relação com as classes "inimigas".

Em 1994, o Racionais se apresentou no Columbia, na época uma badalada boate dos Jardins, frequentada pelo público endinheirado da região. Em reportagem publicada na Folha de S.Paulo ${ }^{8}$, Brown afirmou que havia cantado lá "contra sua vontade" para em seguida dizer: "não vou sair dizendo pra playboyzada: 'não escuta nossas músicas'. Mas deixo bem escuro - e não claro - que a música que faço é para o povo de periferia". Na mesma época, uma reportagem sobre o grupo, publicada na revista $V e j a^{9}$, trazia o seguinte (e impressionante) título: «Pretos, pobres e raivosos».

Tanto a apresentação na boate quanto a reportagem na Veja destacavam-se como episódios isolados na trajetória do Racionais, que se notabilizou pela recusa em aparecer na grande mídia e nos palcos de grandes eventos patrocinados ou casas de shows frequentadas por "burgueses". Porém, como notou Walter Garcia, talvez o principal especialista (na academia) em Racionais MCs, o grupo, que não lança disco de inéditas desde 2002, encontra-se em um "ponto de inflexão" (Garcia, 2011, p. 224).

Quinze anos depois da reportagem na revista Veja, em dezembro de 2009, Mano Brown foi capa da revista Rolling Stone. A matéria, intitulada "Eminência Parda", tinha como foco uma suposta mudança de comportamento de Mano Brown, que teria se tornado mais brando e tolerante. Podemos também dizer, em tom provocativo: mais

8 A matéria em questão é "Gravadoras correm atrás do rap", disponível em http://www1.folha.uol.com.br/fsp/1994/5/07/ilustrada/1.html, publicada em 07/05/1994.

9 Trata-se da edição do dia 12/01/1994. 
branco e tolerante. Afinal, o "preto pobre raivoso" se tornou uma "eminência parda"10. Brown reconhece ter realizado algo como uma autocrítica, por meio da qual reviu seu posicionamento anterior. Em entrevista para a revista Rap Nacional, em 2012, Brown vai mais longe na sua reflexão:

"O Brasil vive um momento novo e nós temos que saber atuar em cima desse momento. Está sobrando um pouco mais de dinheiro, a informação está chegando mais rápido... O Rap carrega certo estigma, acho que foi a pior coisa que eu criei... Q Quando a gente criou o símbolo do Racionais, no final dos anos 80 , era um outro mundo . . Não tem como você esticar o chiclete 25 anos falando das mesmas coisas, como se elas não tivessem mudado".

Essa argumentação buscava explicar a mudança no comportamento do grupo e, em específico, a atuação dos membros individualmente. Em 2007, em editorial na Folha de S. Paulo, Fernando Barros e Silva considerou "um acontecimento" a participação de Mano Brown no programa Roda Viva, da TV Cultura. O espanto do jornalista dá a dimensão de quão arredio era o MC aos convites da grande mídia (se é que se pode considerar a TV Cultura como "grande mídia").

Brown lançou músicas compostas com outros músicos, principalmente a banda Black Rio, com quem gravou "Mulher Elétrica" em 2009 - com levada dançante e letra "despolitizada". No ano seguinte, Brown gravou participação em uma nova versão de "Umbabarauma", de Jorge Ben, em ação promocional da Nike para a Copa do Mundo de 2010, para a qual teria recebido algo perto de $\mathrm{R} \$ 100$ mil. Ele declarou em entrevista à revista Rolling Stone: "Ofereceram um dinheiro de merda e eu meti a faca. Tentei arrancar o máximo". Em abril de 2012, o Racionais tocou no festival Lollapalooza, quebrando o longo jejum de participação em eventos patrocinados por grandes empresas.

Os demais membros do Racionais também reviram muitas de suas posições. No início de 2013, em campanha de lançamento de seu disco solo Contra nós ninguém será, Edi Rock participou do programa Caldeirão do Huck, na Rede Globo ${ }^{11}$. O disco traz participações especiais de artistas sem vínculo com o rap, como Seu Jorge e a cantora Marina de la Riva. Ice Blue participou do clipe "Estilo Gangstar" de Túlio Dek, transmitido pelo Fantástico, também na Globo. O video traz ainda rappers como Helião, Rappin Hood e Edi Rock (além do ex-jogador Ronaldo)

10 Comparando o título das reportagens (da Veja em 1994 e da Rolling Stone em 2009), ele passou de "preto" a "pardo". Para que o trocadilho não nuble a discussão sobre racismo, vale remeter à leitura da entrevista de Mano Brown na Rolling Stone, na qual defende que "os 'pardos' não usufruem do recente fortalecimento da autoestima do povo negro". Ele diz ainda: "No Brasil, você não vê gente da minha cor fazendo comercial, fazendo nada. Se eu não fosse o Mano Brown, seria invisível na rua". Ou seja, Brown defende que os pardos sofrem mais preconceito que os negros - e, nesse sentido, seriam "mais negros que os negros" e não, como sugiro na provocação, "mais brancos".

11 O episódio foi minuciosamente analisado por Walter Garcia (2013). em meio a carros importados, correntes de ouro e dezenas de mulheres em roupas mínimas e em atitude subalterna - elementos que compõem a fórmula do chamado rap ostentação.

Em texto curto publicado em novembro de 2013 no Monde Diplomatique, "O novo caminho de Edi Rock", Walter Garcia (2013) sugere que o Racionais direciona-se para um novo lugar na cultura brasileira, mais próximo do que o autor chama de "música negra no mercado hegemônico". Concordo com a sugestão e proponho ainda que esse realinhamento é também aproximação do Racionais da chamada "Nova Escola" do rap nacional. ${ }^{12}$ Penso também ser possível dizer que, nesse movimento, o grupo afastou-se do posicionamento de classe que havia marcado sua primeira fase, e que propus considerar revolucionário, para adotar o que, na tradição do pensamento social brasileiro, foi chamado de "radicalismo".

Em artigo de 1988, Antonio Candido discute o pensamento radical: "gerado na classe média e em setores esclarecidos das classes dominantes, [o pensamento radical] não é um pensamento revolucionário, e, embora seja fermento transformador, não se identifica senão em parte com os interesses específicos das classes trabalhadoras, que são o segmento potencialmente revolucionário da sociedade" (2004, pp. 193-194). Ainda segundo Candido, o radical passa por cima do antagonismo entre as classes e tende com frequência à harmonização e à conciliação. Se ao longo dos anos 1990 a tendência hegemônica do rap nacional estava marcada por um espírito revolucionário, nos últimos dez anos houve um significativo realinhamento, em direção a um posicionamento radical, para manter a terminologia de Candido. É preciso deixar claro que o rap sempre foi algo plural, abrigando diferentes artistas e concepções. Ao assumir que o Racionais MCs desempenhou e segue desempenhado uma notável centralidade no gênero, permito-me falar em tendências hegemônicas baseando-me sobretudo na trajetória desse grupo. Análises que busquem valorizar as diferentes vertentes dentro do gênero poderão evidentemente lançar luz em outras questões.

Em meu mestrado, acompanhei as principais batalhas de freestyle (rap improvisado) de São Paulo. Segundo seus praticantes, o freestyle é uma vertente do rap que se caracteriza por ser "feita na hora". Pode acontecer como uma brincadeira entre amigos; pode ser um número durante uma apresentação de rap; servir como animação de uma festa de hip hop; ou ainda, se dar no formato de "batalha", como as que se realizam desde 2006, nas noites de sábado, na saída do metrô Santa Cruz em São Paulo ${ }^{13}$. Buscando

12 As expressões old-school e new school, que também aparecem em português como velha escola e nova escola, referem-se a duas grandes fases do rap: grosso modo, anos 80 e início dos 90 seriam velha escola e final dos 90 e anos 2000, nova escola.

13 Acompanhei as batalhas da Santa Cruz entre junho de 2008 e junho de 2011 , tendo comparecido a cerca de 36 eventos dos quais a metade foi registrada em áudio e transcrita. Esse material foi trabalhado em minha dissertação de mestrado, defendida em outubro de 2011. O desafio das batalhas sendo basicamente "zoar o outro", os inscritos se enfrentam em eliminatórias definidas por sorteio; cada etapa é decidida num sistema do 
traçar um perfil social dos MCs "de batalha", elaborei uma entrevista-padrão, que apliquei a quarenta sujeitos. O saldo desse pequeno esforço de sistematização das condições "morfológicas" do campo foi a identificação de um perfil aproximado dos MCs de batalha ${ }^{14}$ : jovens entre $15 \mathrm{e}$ 25 anos, cursando ou tendo concluído o ensino médio, em seguida conciliando pequenos trabalhos com a formação em nível superior (no geral em faculdades particulares) ou, pelo menos, em nível técnico. É o suficiente para distingui-los dos integrantes do Racionais - Mano Brown estudou só até a oitava série.

Logo nas primeiras semanas da batalha da Santa Cruz, em fevereiro de 2006, o então iniciante Emicida enfrentou Cabal, à época um rapper bastante conhecido graças ao hit "Senhorita" - rap que fala de festa e de mulheres, sem nenhum "conteúdo social".

Loiro e de olhos claros, Cabal é filho de uma radialista, morou em Nova York, formou-se em administração e chegou a trabalhar no Citibank. Negro, Emicida é filho de uma empregada doméstica, trabalhou como pedreiro e auxiliar de escritório, concluiu o ensino médio e formou-se técnico em Design pela Escola Arte São Paulo, no Tatuapé.

São duas histórias de vida muito contrastantes. Mas, mesmo assim, houve terreno comum para que eles se enfrentassem em uma batalha de improviso de rap, buscando o reconhecimento do público. Emicida ${ }^{15}$ :

Destaco os dois primeiros versos improvisados por

sua cara é roubar vaga de favelado na USP porque aqui na rima cê não vale nem um cuspe

Não é sem interesse que o tema "ensino superior" tenha surgido durante uma batalha considerada "clássica", quase como um "mito fundador" das batalhas da Santa Cruz. Cabal e Emicida estão em oposição, mas compartilham um universo de possibilidades: o estudo em nível superior. É uma pauta que simplesmente não existia na época do surgimento do Racionais.

Em 2009, Emicida, que tinha então 24 anos, lançou sua primeira Mixtape (ou CD) ${ }^{16}$, gravada com a colaboração de amigos. Ele mesmo fez a arte gráfica, na verdade

tipo "melhor de três", com rounds de trinta segundos para cada participante. Note-se ainda que, na Santa Cruz, quem faz as vezes de júri é o próprio público que, ao cabo de cada round, é chamado a "fazer barulho" para indicar seu rimador preferido.

14 Vale notar que a fronteira entre produtores e consumidores de rap é muito tênue: enorme parcela dos consumidores de rap são também 'fazedores de rima'. No caso dos MCs de batalha, essa confusão entre público e artista é ainda maior.

15 O video da batalha encontra-se disponível no site de compartilhamento YouTube. O link disponibilizado pelo internauta "Arcbilly" contava em 19/05/2011 449.096 acessos. Para uma análise mais detalhada dessa batalha, ver Teperman (2011)

16 Pra Quem Já Mordeu Um Cachorro Por Comida, Até Que Eu Cheguei Longe (2009). Mixtape é o termo usado pelos rappers, desde a época das fitas cassete, para uma auto-produção. dois carimbos com os quais marcava um pedaço de papel craft, comprado em rolo e cortado no tamanho do CD. Com a ajuda do padrasto, que recebia uma comissão pelo trabalho, ele gravava uma a uma as mídias em seu computador. Para as vendas, o próprio artista carregava sempre os discos na mochila, vendendo depois de seus shows ou durante eventos de hip hop. Seu irmão Evandro tornou-se seu produtor, e naquele mesmo ano a mixtape vendeu mais de 10 mil unidades ${ }^{17}$.

Com o sucesso da empreitada, mais membros da família passaram a trabalhar na equipe. Compraram novos computadores, uma impressora melhor e passaram a gravar os CDs em produção quase ininterrupta ao longo do dia, enquanto atendiam outras demandas ligadas à carreira do artista. Sua empresa Laboratório Fantasma é hoje o mais bem sucedido negócio no hip hop nacional. Além de agenciar Emicida e outros cinco artistas, vende CDs, DVDs, roupas e acessórios.

Esse pensamento "empreendedor" é uma marca característica da atual geração de rappers. Há uma relação descomplexada com a ideia de mercado, com a autopromoção e com a grande mídia. Pouco após o lançamento de sua primeira Mixtape, Emicida fez uma campanha publicitária para a Nike. Sempre divulgou em seu blog as reportagens feitas a seu respeito na grande mídia (revistas Época e Bravo!, jornais Folha de S. Paulo e O Estado de S. Paulo, entre outros) e participou dos principais programas de divulgação da TV Globo (Altas Horas, Jô Soares, Som Brasil, Xuxa, etc.). Promove diversas colaborações com artistas da MPB (como o grupo Mão de Oito e a cantora Mariana Aydar), do pop (como a cantora Pitty e o grupo NX Zero), assim como com artistas de Funk (como o MC Guimê).

Apesar das diferenças na origem social, aparência e escolha dos temas na construção das letras, Cabal compartilha com Emicida o tipo de atuação no mercado da música. Mantém um blog e intensa divulgação por internet, esteve nos mesmos programas de TV e também colaborou com artistas de outros gêneros - notadamente, gravou com a dupla Chitãozinho e Xororó, em disco que veio a ganhar o Grammy Latino de "melhor album de música regional e raízes". Cabal defende que não é preciso "cantar desgraças para fazer um bom rap", formulação que encontra eco em declarações recentes de Mano Brown e Edi Rock, dentre outros $^{18}$. Aliás, os integrantes do Racionais também mudaram de posição no que diz respeito à relação com a música como produto, como vimos nas declarações de Brown a respeito da colaboração com a Nike.

A relativa melhoria no nível de renda, a democratização do acesso à internet banda larga e à tecnologia em geral, associados à maior escolarização, são algumas das mudanças recentes que impactaram as trajetórias de produtores e consumidores de rap. Como vimos, Emicida concluiu o ensino médio e formou-se técnico em design. Muitos outros MCs de sua geração, como Kamau, Projota

17 O preço era R\$ 3 para compra em mãos e $\mathrm{R} \$ 5$ para compra por internet. 18 Ver as entrevistas publicadas nas revistas Rap Nacional e Rolling Stone. 
e Marcello Gugu, têm nível superior completo. Se a expressão "nova classe média"19 é precipitada ou imprecisa, é certo que as transformações do Brasil nos últimos 15 anos bagunçaram a identidade de classe no rap.

Na etnografia Lá do Leste, Rose Satiko e Carolina Caffé (2013) flagram as reações de rappers da Cidade Tiradentes diante da perda de espaço do gênero para o funk. Copio a seguir um trecho de um depoimento de Douglas de Souza Monteiro, membro da Família RDM ${ }^{21}$ :

Antigamente o bairro era rua de barro, nós esperávamos meia-noite pra sair água de um cano, e aquela fila enorme de gente com balde. Aí o rap retratava aquilo. Todo mundo gostava de ouvir porque era um protesto, todo mundo se unia pra protestar contra aquilo. Por uma rua asfaltada... Conforme nós fomos conseguindo isso, acho que as pessoas foram se dividindo.

19 A expressão "nova classe média" é problemática, como sublinharam vários dos autores que participaram do Seminário $A$ "nova classe média": Familias em Mudança?, organizado pelo LEFAM-IPUSP, no dia 12 de agosto de 2013.

21 A família é uma extensão do grupo de rap Rapaziada do Morro (RDM).É composta por amigos, vizinhos e familiares que apoiam e acompanham o grupo. Frequenta os shows, divulga os eventos, compartilha ideias e participa dos churrascos e dos encontros nas lan houses.
O depoimento de Douglas encontra eco nas declarações recentes de Mano Brown e Edi Rock. Arrisco dizer que o enfraquecimento do rap como fenômeno de classe é inversamente proporcional ao seu fortalecimento como gênero musical de mercado. Esse fortalecimento se mostra na notável pluralidade de subgêneros, assim como na presença do rap como música produzida e consumida em vários estratos sociais e ao longo de todo o território nacional. Entre os diversos subgêneros, podemos citar o rap indígena, o rap gospel, o rap ostentação, o rap feito por mulheres e aquele que segue assumindo uma posição revolucionária, como o do grupo Facção Central.

Entretanto, sugiro que a vertente hegemônica do rap, representada ainda pelo Racionais, vem aproximandose de um discurso que pode ser caraterizado, nos termos de Antonio Candido, de radical. Segundo o autor, "o radical é sobretudo um revoltado, e embora seu pensamento possa avançar até posições realmente transformadoras, pode também recuar para posições conservadoras" (2004, p. 194). O rap segue sendo um gênero vigoroso, com enorme potencial contestador e transformador. Muitos MCs declaram sua preocupação em fazer com que o rap ocupe mais espaço no campo da produção cultural do Brasil. O esforço é legítimo e vem sendo vitorioso, mas é preciso considerá-lo no contexto da realocação do rap no grande caldeirão - às vezes morno, outras em ebulição - da cultura brasileira.

\section{Radical rap and the "new middle class"}

Abstract: This article discusses the recent change in stance that refers to rap and rappers in the field of cultural production in Brazil. The group Racionais MCs, a core for the domestic rap, so much so that they have just determined a hegemonic trend for this genre, has been moving away from that revolutionary stance that was the mark of their initial years. I set forth that the increase in power of consumption and democratization in the access to technology and education are aspects that leave a mark on the experience of the rap generation (called the "new school"), personified in Emicida, and have led to the repositioning of the Racionais. I redeem what was said by Antonio Candido to propose that this new position could be deemed "radical".

Keywords: New middle class, Contemporary Brazilian society, Racionais MCs, Brazilian, Popular Brazilian Music.

\section{Le rap radical et la 'nouvelle classe moyenne'}

Résumé: Cet article discute la position rélative du rap et des rappers dans le champ de la production culturelle au Brésil. Récemment, Le groupe Racionais MCs, qui occupe une position centrale dans le rap brésilien et détermine les tendances principales dans le genre, est en train d'abandonner l'attitude révolutionaire qui a marquée les premières annèes de son éxistance. Je propose que la monté du pouvoir d'achat et la démocratisation de l'accès à la technologie et à l'éducation sont des aspects qui marquent l'experience de la nouvelle generation du rap (ainsi nommée la "nouvelle école"), personifiée par le rappeur Emicida, et qui ont provoqué le repositionnement du groupe Racionais. J'utilise un concept de Antonio Candido et je propose que cette nouvelle position peut être consideré comme "radicale".

Mots-clés: Nouvelles Classes moyennes, Société Brésilienne Contemporaine, Racionais MCs, Rap Brésilien, Musique Populaire Brésilienne. 


\section{El rap radical y la "nueva clase media"}

Resumen: Este artículo discute la reciente alteración en la posición que respecta el rap y los rappers en el campo de la producción cultural en el Brasil. El grupo Racionais MCs, tan central al campo del rap nacional que acaba por determinar la tendencia hegemónica del género, se aleja del posicionamiento revolucionario que lo marcó durante sus años iniciales. Propongo que el aumento del poder de consumo y la democratización del acceso a la tecnología y a la educación son aspectos que marcan la experiencia de la nueva generación del rap (la así llamada "nueva escuela"), personificada en Emicida, y que han provocado el reposicionamiento de los Racionais. Recupero una formulación de Antonio Candido para proponer que esa nueva posición podría considerarse como "radical".

Palabras clave: Nueva Clase Media, Sociedad brasileña contemporânea, Racionais MCs, Rap Brasileño, Música Popular Brasileña.

\section{Referências}

Alves, C. (2004). Pergunte a quem conhece: Thaide. São Paulo, SP: Labortexto.

Buzo, A. (2010). Hip-hop: dentro do movimento. Rio de Janeiro, RJ: Aeroplano.

Candido, A. (2004). Vários escritos. Rio de Janeiro, RJ: Ouro sobre Azul.

Felix, J. B. J. (2005). Hip hop: cultura e politica no contexto paulistano (Tese de doutorado). Faculdade de Filosofia, Letras e Ciências Humanas, Universidade de São Paulo, São Paulo.

Frúgoli Jr., H. (2000). Centralidade em São Paulo: trajetórias, conflitos e negociações na metrópole. São Paulo, SP: EDUSP.

Garcia, W. (2003). Ouvindo Racionais. Teresa, (4-5), 167180.

Garcia, W. (2007). Diário de um detento: uma interpretação. In A. Nestrovski (Org.), Lendo canções. São Paulo, SP: Publifolha.

Garcia, W. (2011). Sobre uma cena de "Fim de Semana no Parque", do Racionais MC's. Estudos Avançados, 25(7), 221-235.

Garcia, W. (2013). O novo caminho de Edi Rock. Le Monde Diplomatique. Recuperado de http://www.diplomatique. org.br/artigo.php?id=1538

Guasco, P. P. M. (2001). Num pais chamado periferia: identidade e representação da realidade entre os rappers de São Paulo (Dissertação de Mestrado). Faculdade de Filosofia, Letras e Ciências Humanas, Universidade de São Paulo, São Paulo.

Herschmann, M. (2005). O funk e o hip-hop invadem a cena. Rio de Janeiro, RJ: UFRJ.

Kehl, M. R. (1999). Radicais, Raciais, Racionais - a grande fratria do rap na periferia de São Paulo. São Paulo em Perspectiva, 13(3), 95-106.

Leal, S. J. M.. (2007) Acorda hip-hop!: despertando um movimento em transformação. Rio de Janeiro, RJ: Aeroplano.

Macedo, M. (2004). Serviço de Preto: uma faceta do consumo da juventude afro-paulista. In 28 Reunião Anual da Associação Nacional de Pós-Graduação e Pesquisa em Ciências Sociais (ANPOCS). Caxambu, MG.
Macedo, M. (2007). Baladas black e rodas de samba da terra da garoa. In J. G. Magnani (Org.), Jovens na metrópole: etnografias de circuitos de lazer, encontro e sociabilidade. São Paulo, SP: Terceiro Nome.

Nascimento, E. P. (2006). Literatura marginal: os escritores de periferia entram em cena (Dissertação de Mestrado). Faculdade de Filosofia, Letras e Ciências Humanas, Universidade de São Paulo, São Paulo.

Sandroni, C. (2001). Feitiço decente: transformações do samba no Rio de Janeiro, 1917-33. Rio de Janeiro, RJ: Jorge Zahar.

Satiko, R. S. G. H., \& Caffé, C. (2013). Lá do leste - uma etnografia audiovisual compartilhada. São Paulo, SP: Humanitas.

Silva, J. C. (2007). Juventude e segregação urbana na cidade de São Paulo: os números da vulnerabilidade juvenil e a percepção musical dos rappers. Ponto Urbe - Revista do Núcleo de Antropologia Urbana, 1 (versão 1.0.).

Silva, J. C. (1998). Rap na cidade de São Paulo: música, etnicidade e experiência urbana (Tese de Doutorado). Universidade Estadual de Campinas, Campinas, SP.

Singer, A. (2012). Os sentidos do Lulismo. São Paulo, SP: Companhia das Letras.

Teperman, R. (2010). Emicida versus Cabal - encenando conflitos reais. Iara, 3, 119-140.

Teperman, R. (2011). Tem que ter suingue - batalhas de freestyle no metrô Santa Cruz (Dissertação de Mestrado). Faculdade de Filosofia, Letras e Ciências Humanas, Universidade de São Paulo, São Paulo.

Vianna, H. (1988). O mundo funk carioca. Rio de Janeiro, RJ: Jorge Zahar.

Vianna, H. (1995). O mistério do samba. Rio de Janeiro, RJ: Jorge Zahar.

Vianna, H. (2006). Paradas do sucesso periférico. Revista Sexta-Feira, 8, 19-29.

Wisnik, J. M. (2004). Sem receita. São Paulo, SP: Publifolha. Wisnik, J. M. (2008). Veneno remédio: o futebol e o Brasil. São Paulo, SP: Companhia das Letras.

Recebido: 16/03/2014 Aceito: 30/08/2014 